\title{
Возможности биомедицинского применения модифицированных пектинов
}

\author{
(C) 2021 Мамедов Э.И., Дергунова Е.С., Калмыкова Е.Н. \\ Липеикий государственный технический университет, Липецฺк
}

Поступила в редакцию 9.10.2020 г.

DOI: $10.17308 /$ sorpchrom.2021.21/3222

В работе приведен краткий обзор за последние 10-15 лет по имеющимся методам модификации пектиновых полисахаридов (алкилирование, амидирование, тиолирование, сульфатирование). Дана краткая характеристика структурных особенностей различных пектиновых полисахаридов (гомогалактуронана, рамногалактуронана, ксилогалактуронана). Каждый метод содержит информацию по соответствующим химическим реакциям взаимодействия пектиновых полисахаридов с модифицирующими реагентами, а также сведения о применении модифицированных пектинов в медицине, пищевой и фармацевтической промышленности.

Например, ацетилированные пектины могут быть использованы как стабилизаторы и эмульгаторы пищевых систем, а также влиять на механизм высвобождения ибупрофена (слабокислого препарата) по всему желудочно-кишечному тракту.

Высокожелирующие свойства амидированных пектинов позволяют изготавливать гидрогелевые шарики, которые могут быть использованы при доставке лекарственных препаратов, специфических для толстой кишки (таких как индометацин и сульфаметоксазол) и предназначаться для перорального приема инсулина.

Тиолированные пектины перспективны в применении их в качестве мукоадгезивных полимеров. Данное свойство позволяет обеспечить значительно более глубокое проникновение лекарственного препарата (малеата тимолола) через роговицу глаза, что открывает возможность использования модифицированного таким образом пектинов в офтальмологии.

Сульфатированные пектины интересны в силу своего значительного влияния на физиологические функции полисахаридов, таких как антиоксидантная, противовоспалительная, противоопухолевая, противомикробная и противовирусная (анти-ВИЧ-инфекционная активность). Одним из характеристик сульфата пектина является его антикоагулянтная активность и антитромботическое действие. Исследования показали, что замена карбоксильной группы на сульфатную в цитрусовом пектине увеличивает оба вышеупомянутых эффекта, не влияя на геморрагический. Кроме того, данное производное пектина также проявляет улучшенное антимикробное действие против Bacillus cereus и Vibrio fischeri.

Имеющиеся методы модификации пектиновых полисахаридов раскрывают возможность более эффективного практического использования природных биополимеров углеводной природы не только в пищевой и косметической промышленности, но и для медицинских целей. Поиск новых путей изменения химической структуры гликанов способствует получению веществ с заданными свойствами, которые еще только предстоит исследовать в более широком масштабе.

Ключевые слова: пектины, алкилирование, амидирование, тиолирование, сульфатирование, применение в медицине.

\section{Введение}

Пектины - высокомолекулярные, биосовместимые, нетоксичные, анионные природные полисахариды, синтезируемые высшими растениями.

В клеточной стенке можно обнаружить различные пектиновые полисахариды, включая гомогалактуронаны, 


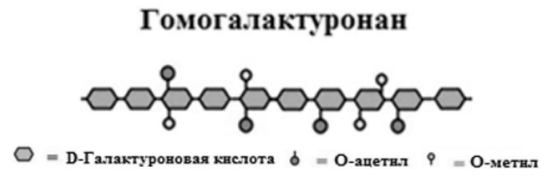

Рис. 1. Структура гомогалактуронана / Fig. 1. Homogalacturonan structure

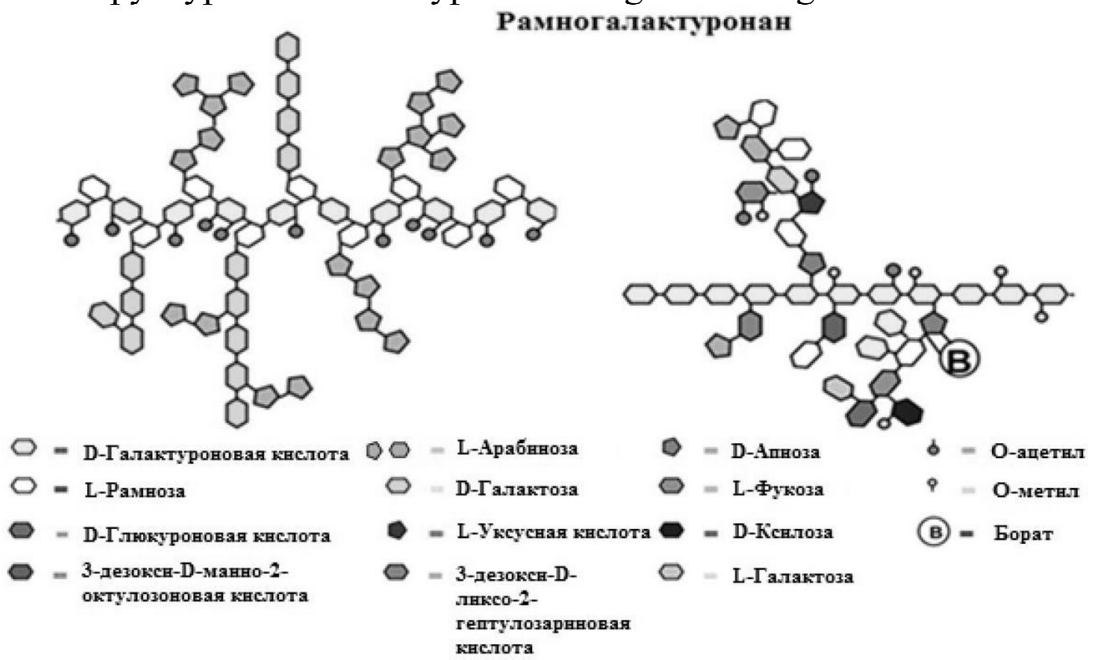

Рис. 2. Структура рамногалактуронана / Fig. 2. Rhamnogalacturonan structure ксилогалактуронан

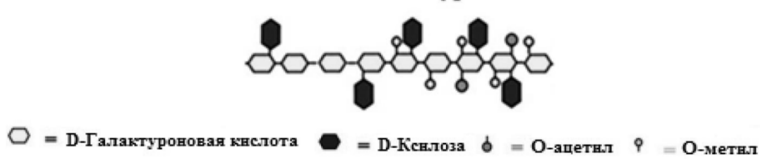

Рис. 3. Структура ксилогалактуронана / Fig. 3. Xylogalacturonan structure

рис.1; рамногалактуронаны, рис. 2, ксилогалактуронаны, рис. 3 и др. [1]. Соотношение между полисахаридами варьируется, но обычно наиболее распространенным полисахаридом, составляющим около $65 \%$ пектинов является гомогалактуронан, в то время как рамногалактуронан-І составляет от 20 до $35 \%$ [2].

Пектиновые полисахариды представляют собой не отдельные молекулы, а ковалентно связанные домены. Неразветвленные гомополимерные цепи $\alpha-1,4$-связанного D-GalA описаны как галактуронан. Основная цепь остатков GalA может быть заменена в различных положениях другими моносахаридными фрагментами.

Рамногалактуронан и ксилогалактуронан и являются второстепенными компонентами, каждый из которых превышает $10 \%[2,3]$.

В ксилогалактуронане ксилоза присоединяется по 3-положению к некоторым остаткам галактуроновой кислоты. Дополнительные остатки ксилозы могут быть присоединены к первому ксилоз-

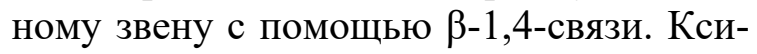
логалактуронаны особенно широко распространены в репродуктивных тканях животных, но также присутствуют в растениях, например, в листьях Arabidopsis [3]. У водных покрытосеменных, таких как Lemna u Spirodela, галактуроновый остов декорирован D-апиофуранозой по О-2 или О-3 [4-6].

Пектины получили широкое распостранение в пищевой промышленности как функциональный ингредиент, способный образовывать водные гели, и поэтому используемый как желирующий и стабилизирующий агент. Эти кислые полисахариды используются для приготовления джемов и желе, витаминов, концентратов фруктовых напитков, фруктовых соков, десертов и кисломолочных продуктов. Наряду с отличными желирующими свойствами, они характеризуются 
хорошей биосовместимостью и отсутствием токсичности, а также способностью к биодеградации, что делает пектины привлекательными в качестве новых биополимерных материалов, которые можно использовать в косметологии, фармацевтической промышленности, и медицине.

Большое число публикаций посвящено изучению сорбции ионов двухвалентных металлов $\left(\mathrm{Ca}^{2+}, \mathrm{Zn}^{2+}, \mathrm{Cu}^{2+}\right.$ и $\left.\mathrm{Pb}^{2+}\right)$, пектиновыми полисахаридами, полученными из различных растений (персики, яблоки, подсолнечник) [7]. Например, в работе [8, 9] авторы предлагают использовать модифицированные пектины для очистки сточных вод от ионов тяжелых металлов $\left(\mathrm{Pb}^{2+}, \mathrm{Cu}^{2+}, \mathrm{Zn}^{2+}, \mathrm{Mn}^{2+}\right.$, $\left.\mathrm{Co}^{2+}, \mathrm{Sr}^{2+}, \mathrm{Cs}^{+}, \mathrm{Zr}^{4+}\right)$.

Пектины можно также использовать в качестве биосорбентов. Показана эффективность сорбции тонкими полисахаридными пленками на основе зостерана ионов тяжёлых металлов $\left(\mathrm{Pb}^{2+}\right.$ и $\left.\mathrm{Cd}^{2+}\right)$ из водных растворов [10]. Другим активно развивающимся направлением исследований является создание новых лекарств с использованием композиций на основе пектиновых веществ, благодаря их способности образовывать гель в присутствии ионов металла [11].

Полисахариды различной природы способны не только очищать организм от катионов и токсичных метаболитов, но и наоборот, служить матриксом для сорбции биологически активных низкомолекулярных веществ, которые необходимо ввести в организм в качестве лекарственных препаратов [12]. Наряду с поликатионитами можно также использовать и пектины, являющиеся полисахаридами анионной природы.

В последние годы интерес исследова- телей направлен на разработку различных методов модификации пектинов с целью получения новых материалов с заданными свойствами. В статье [13] представлены сведения о различных методах, используемых для модификации пектиновых веществ (алкилирование, амидирование, сульфатирование, окисление, удлинение цепи путем кросс-связывания, деполимеризация и ферментативная деградация).

\section{Ацетилирование гидроксильной группы}

Ацетилирование является одним из наиболее важных методов алкилирования гидроксильных групп в пектинах. Пектины, получаемые из некоторых растений, например, из сахарной свеклы, картофеля и подсолнечника, естественно могут быть ацетилированы по О-2 и (или) O-3 положению галактуроновой кислоты, рис. 4 [13].

Такая этерификация снижает стабильность связывания кальция и пектина [14, 15], сильно препятствуя гелеобразованию, при этом полное ингибирование гелеобразования происходит, когда один из восьми остатков D-галактуроновой кислоты ацетилируется по О-2 или О-3 положению. Это объясняется стерическим эффектом ацетильных групп, которые в определенной степени препятствуют доступу ионов кальция к близкому соседству двух карбоксильных групп. Авторами отмечено, что эффект ацетилирования можно также объяснить изменением конформации при модификации полисахарида и образованием комплексов [16].

Наличие ацетильных групп может снизить прочность связывания катиона с отдельными фрагментами галактуроновой кислоты или затруднить формирование

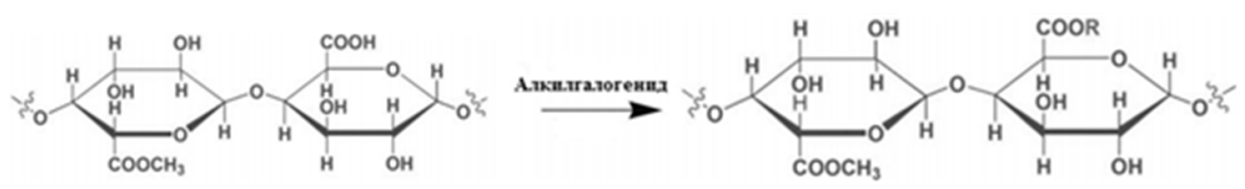

Рис. 4. Алкилирование пектина алкилгалогенидом

Fig. 4. Alkylation of pectin with an alkyl halide 


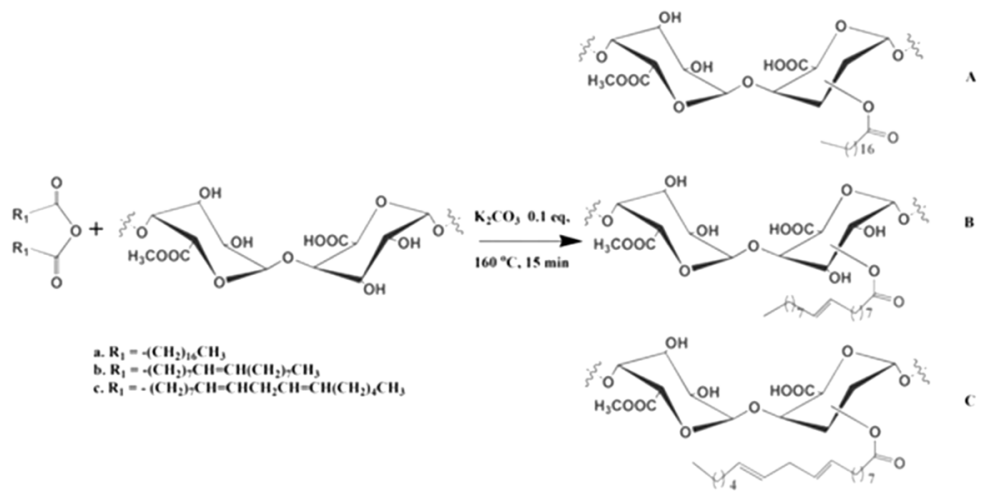

Рис. 5. Этерификация ОН-групп пектинов с использованием пальмитиновой, олеиновой или линолевой кислоты

Fig. 5. Esterification of OH-groups of pectins using palmitic, oleic, or linoleic acid

полимером конформаций, необходимых для связывания.

Однако ацетилированные пектины имеют некоторые другие возможности для практического применения. Они могут быть использованы как стабилизаторы и эмульгаторы [17]. Кроме того, установлено, что ацетилированные пектины способны влиять на механизм высвобождения ибупрофена (слабокислого препарата) по всему желудочно-кишечному тракту из-за снижения полярности и растворимости пектина.

В основном ацетилирование проводили в растворитель-катализаторных системах с ангидридом уксусной кислоты. Растворителем может быть диметилсульфоксид или формамид, а катализатором пиридин или N-метилимидазол.

Чтобы пектины обладали более выраженными свойствами, ангидриды жирных кислот также предварительно алкилировали по гидроксильной группе. В работе [18] проводили этерификацию групп пектина с использованием пальмитиновой, олеиновой или линолевой кислоты.

Все реакции этерификации проводят при механическом измельчении пектина с соответствующими ангидридами жирных кислот в присутствии каталитического количества основания $\mathrm{K}_{2} \mathrm{CO}_{3}$ при отсутствии растворителя, рис. 5 [13]. Эта химическая модификация была признана эффективной, быстрой, экономичной и экологичной, а также расширила область применения пектинов по мере уменьшения их сорбции водой.

\section{Амидирование}

Простейшими, но наиболее широко используемыми являются амидированные пектины, содержащие первичные аминогруппы -CO-NH2, рис. 6 [13]. Это важные производные пектина, имеющиеся на рынке и используемые в технологии приготовления пищи с хорошими желирующими свойствами и низкой чувствительностью к ионам $\mathrm{Ca}^{2+}$ и кислотности среды.

Кроме того, гели амидированных пектинов термообратимы. Их можно нагревать и после охлаждения снова переводить в твердое состояние, тогда как обычные пектин-гели останутся жидкими. Их высокожелирующие свойства позволяют изготавливать гидрогелевые шарики, ко-

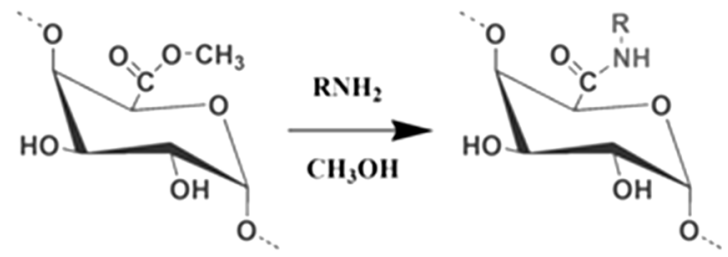

Рис. 6. Амидирование пектинов / Fig. 6. Amidation of pectins 
торые могут быть использованы при доставке лекарственных препаратов, специфических для толстой кишки, таких как индометацин и сульфаметоксазол [19] и использоваться для перорального приема инсулина [20]. Распространенным методом данного вида пектинового препарата является аммонолиз метилэфирных групп высокометоксильных пектинов с аммиаком в безводном метаноле.

\section{Тиолирование}

Исследования по тиолированию пектинов получили широкое распространение. Это чрезвычайно активный субъект изучения благодаря интересу в развитии «второго поколения» мукоадгезивов. Природные полисахариды относятся к «первому поколению» мукоадгезивных полимеров, которые могут нековалентно взаимодействовать со слоем слизи, но это мукоадгезивное свойство является слабым. Свойства мукоадгезивных полимеров могут быть улучшены их тиолированием. Тиомеры способны образовывать ковалентные дисульфидные связи с цистеиновыми субдоменами слизистого слоя на слизистой оболочке.

Тиолсодержащие лиганды могут быть введены в пектиновую цепь с образованием амидных или сложноэфирных связей. В работе [21] приведены результаты исследования авторов по способу синтеза тиолированного пектина путем его этерификации тиогликолевой кислотой в присутствии соляной кислоты, рис. 7.

В результате тиолирования повышается мукоадгезивная способность пектинов. Авторами также сообщено об использовании наночастиц, полученных на основе тиолированного пектина, которые
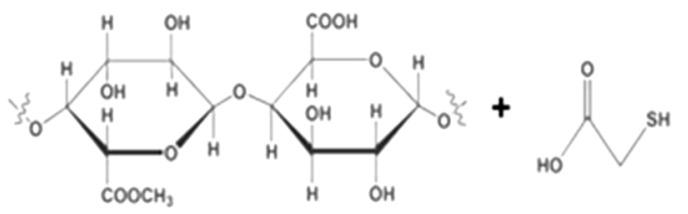

обеспечивают значительно более глубокое проникновение лекарственного препарата (тимолола малеата) через роговицу глаза [22]. Полученные результаты открывают перспективу использования модифицированных таким образом пектинов в офтальмологии.

\section{Сульфатирование}

Замещение гидроксильных групп в структуре биополимера сульфатными группами интересно в силу своего значительного влияния на физиологические функции полисахаридов, таких как антиоксидантная, противовоспалительная, противоопухолевая, противомикробная и противовирусная (анти-ВИЧ-инфекционная активность). Недавно появились результаты по исследованию влияния введения сульфатных групп в пектиновые макромолекулы для улучшения антимикробной, антикоагулянтной и антитромботической активности $[23,24]$.

Сульфатирование пектинов обычно осуществляется с использованием серной кислоты, хлорсульфоновой кислоты, монометилового сульфата, сульфотриоксида, хлористого сульфурила или сульфаминовой кислотой в присутствии формамида, диметилсульфоксида, триметиламина и пиридина. Хлорсульфоновая кислота считается наиболее активным агентом сульфатирования [25]. Однако, метод с использованием хлорсульфоновой кислоты приводит к гидролизу или деструкции полисахаридной цепи. Кроме того, степень замещения может быть очень низкой -0.15 . В литературе имеются также данные по использованию некоторых других сульфатирующих агентов, например, трисульфонатед амин

Рис. 7. Этерификация пектина тиогликолевой кислотой в присутствии соляной кислоты

Fig. 7. Esterification of pectin with thioglycolic acid in the presence of hydrochloric acid 
натрия $\left[\mathrm{N}\left(\mathrm{SO}_{3} \mathrm{Na}\right)_{3}\right]$, используемых для получения сульфатов пектинов [23].

Сульфатирование галактуронана монометилсульфатом пиридина. Сульфатирование монометилсульфатом пиридина проводили по методу [26]. К триэтиламмониевой соли галактуронана добавляли диметилфорамид (ДМФА), смесь перемешивали, затем добавляли разное количество монометилсульфата пиридина. Далее реакцию проводили при фиксированной температуре в течение определенного времени. Реакционную смесь охлаждали, добавляли гидроксид натрия, диализовали против дистиллированной воды и лиофилизовали. Сульфатирование галактуронана монометилсульфатом пиридином протекает по следующей схеме, рис. 8 [27].

Сульфатирование галактуронана пиридинсульфотриоксидом. Сульфатирование пиридинсульфотриоксидом проводили по методу [28]. Для получения пиридинсульфотриоксида к предварительно охлажденному пиридину медленно при постоянном перемешивании приливали концентрированную хлорсульфоновую кислоту. Полученную смесь выдерживали, получали пиридинсульфотриоксид в виде белых кристаллов, которые растворяли в ДМФА и использовали для сульфатирования галактуронана. Для сульфатирования галактуронана к его триэтиламмониевой соли приливали ДМФА, смесь перемешивали при постоянной температуре, добавляли весь ранее полученный раствор пиридинсульфотриоксида и далее проводили реакцию при разных температурах. Реакционную смесь охлаждали, добавляли гидроксид натрия, диализовали против дистилированной воды и лиофилизовали.

Сульфатирование галактуронана пиридинсульфотриоксидом протекает по следующей схеме, рис. 9 [27].

Сульфатирование хлорсульфоновой кислотой проводили по методу [29]. К триэтиламмониевой соли галактуронана и бергенана приливали ДМФА, добавляли п-толуолсульфокислоту, смесь перемешивали, добавляли хлорсульфоновую кислоту и далее реакцию проводили при фиксированной температуре. Реакционную смесь охлаждали, добавляли гидроксид натрия, диализовали против дистиллированной воды и лиофилизовали.

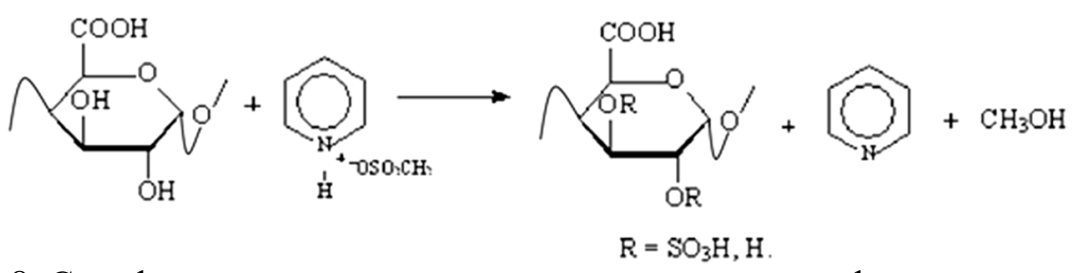

Рис. 8. Сульфатирование галактуронана монометилсульфатом пиридином

Fig. 8. Sulphation of galacturonan with pyridine monomethyl sulphate

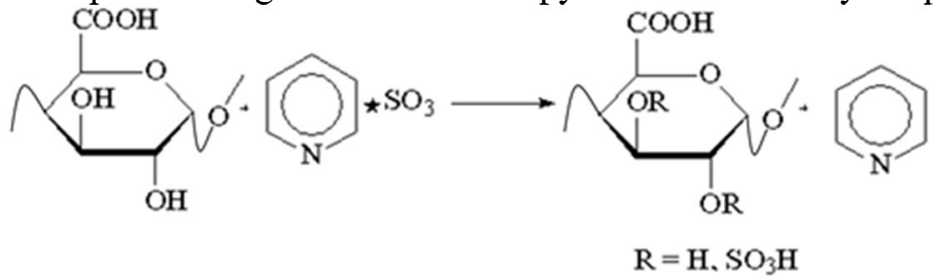

Рис. 9. Сульфатирование галактуронана пиридинсульфотриоксидом

Fig. 9. Sulphation of galacturonan with pyridine sulphotrioxide

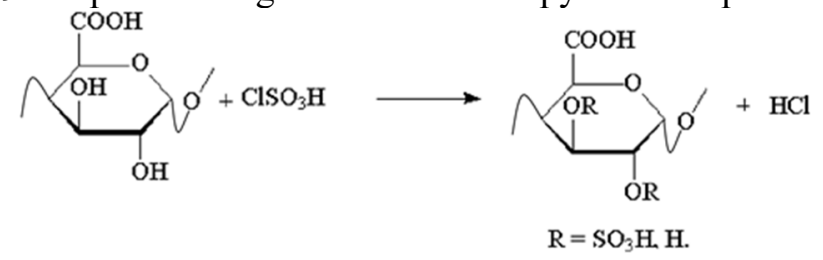

Рис. 10. Сульфатирование галактуронана хлорсульфоновой кислотой

Fig. 10. Sulphation of galacturonan with chlorosulfonic acid 
Дополнительно проводили сульфатирование галактуронана при добавлении хлорсульфоновой кислоты и лемнана.

Сульфатирование галактуронана хлорсульфоновой кислотой протекает по следующей схеме, рис. 10 [27].

Одним из характеристик сульфата пектина является его антикоагулянтная активность и антитромботическое действие. Исследования показали, что замена карбоксильной группы на сульфатную в цитрусовом пектине увеличивает оба вышеупомянутых эффекта, не влияя на геморрагический. В работе [30] продемонстрировано, что сульфатированный пектин показал антикоагулянтные свойства, сравнимые с действием гепарина.

\section{Список литературы}

1. Harholt J., Suttangkakul A., Scheller H. // Plant Physiology. 2010. Vol. 153. pp. 384-395.

2. Mohnen D. // Curr Opin Plant Biol. 2008. Vol. 11(3). pp. 266-277.

3. Zandleven J., Sorensen S., Harholt J., Beldman G. et al. // Phytochemistry. 2007. Vol. 68. pp. 1219-1226.

4. Hart D., Kindel P. // Biochem J. 1970. Vol. 116. pp. 569-579.

5. Ovodov Y., Ovodova R., Bondarenko O., Krasikova I. // Carbohydr Res. 1971. Vol. 18. pp. 311-318.

6. Longland J., Fry S., Trewavas A. // Plant Physiol. 1989. Vol. 90. pp. 972-976.

7. Халиков Д.Х., Мирзоева Р.С., Бободжонова Г.Н., Горшкова Р.М. и др. // Доклады Академии наук Республики Таджикистан. 2017. T. 60. № 7-8. C. 333-341.

8. Li F.T., Yang H., Zhao Y., Xu R. // Chinese Chemical Letters. 2007. Vol. 18. pp. 325-328.

9. Игнатьева Г.Н., Овсюк Т.И. // Хранение и переработка сельхозсырья. 2001. № 8. С. 2731.

10. Рогожников Н.А., Калмыкова Е.Н., Архипова А.А. // Фундаментальная гликобиология. 2018. С. 102-110.

11. Халикова М.Д. Дисс. канд. мед. наук. Душанбе. 2009. 24 с.

12. Мироненко Н.В., Брежнева Т.А., Шкутина И.В., Селеменев В.Ф. // Сорбиионные и хроматографические прочессы. 2015. Т. 15. № 1. С. 74-84.
Специфическая антикоагулянтная активность сульфатированных пектинов зависит от вида растений, моносахаридного состава пектина, степени его сульфатирования и молекулярного веса. Помимо антикоагулянтной и антитромботической активности, это производное пектина также проявляет улучшенное антимикробное действие против Bacillus cereus и Vibrio fischeri.

Поиск новых путей модификации пектинов способствует получению веществ с новыми свойствами, которые позволят более эффективно использовать углеводные биополимеры для пищевой и фармацевтической промышленности, а также для медицинских целей.

13. Chen J., Liu W., Liu C., Li T. et al, Critical Reviews in Food Science and Nutrition. 2015. Vol. 55(12). pp. 1684-1698.

14. Kohn R., Furda I. // Collection of Czechoslovak Chemical Communications. 1968. Vol. 42. pp. 731-744.

15. Kohn R., Malovikova A. // Collection of Czechoslovak Chemical Communications. 1978. Vol. 43. pp. 1709-1719.

16. Renard C., Jarvis M. // Carbohydrate Polymers. 1999. Vol. 39. pp. 209-216.

17. Leroux J., Langendorff V., Schick G., Vaishnav V. et al. // Food Hydrocolloids. 2003. Vol. 17. pp. 455-462.

18. Monfregola L., Bugatti V., Amodeo P., De Luca S. et al. // Biomacromolecules. 2011. Vol. 12. pp. 2311-2318.

19. Munjeri O., Collett J., Fell J. // Journal of Controlled Release. 1997. Vol. 46. pp. 273-278.

20. Musabayane C., Munjeri O., Bwititi P., Osim E. // Journal of Endocrinology. 2000. Vol. 164. pp. 1-6.

21. Sharma R., Ahuja M. // Carbohydrate Polymers. 2011. Vol. 85. pp. 658-663.

22. Sharma R., Ahuja M., Kaur H. // Carbohydrate Polymers. 2012. Vol. 87. pp. 1606-1610.

23. Fan L., Gao S., Wang L., Wu P. et al. // Journal of Applied Polymer Science. 2012. Vol. 124. pp. 2171-2178.

24. Maas N., Gracher A., Sassaki G., Gorin P. et al. // Carbohydrate Polymers. 2012. Vol. 89. pp. 1081-1087.

25. Vityazev F., Golovchenko V., Patova O., Drozd N. et al. // Biochemistry. 2010. Vol. 75. pp. 759-768. 
26. Takano R., Nagai T., Wu X., Xu X. et al., // Journal of Carbohydrate Chemistry. 2000. Vol. 19. pp. 1185-1190.

27. Витязев Ф.В., Головченко В.В., Патова О.А., Дрозд Н.Н. и др. // Биохимия. 2010. Т. 75. № 6. С. 857-867.
28. Mahner C., Lechner M., Nordmeier E. // Carbohydrate Research. 2001. Vol. 33. pp. 203208.

29. Vogt S., Heinze T., Rottig K., Klemm D. // Carbohydrate Research. 1995. Vol. 266. pp. 315-320.

30. Bae I., Joe Y., Rha H., Lee S. et al. // Food Hydrocolloids. 2009. Vol. 23. pp. 1980-1983.

\title{
Possibilities for the biomedical application of modified pectins
}

\author{
(C) 2021 Mamedov E.I., Dergunova E.S., Kalmykova E.N. \\ Lipetsk State Technical University, Lipetsk, Russian Federation
}

\begin{abstract}
The study provides a brief overview of the available methods for modifying pectin polysaccharides (alkylation, amidation, thiolation, sulfation) over the past 10-15 years. A brief description of the structural features of various pectin polysaccharides (homogalacturonan, rhamnogalacturonan, xylogalacturonan) is provided in the study. Each method contains information on the corresponding chemical reactions of the interaction of pectin polysaccharides with modifying reagents, as well as information on the use of modified pectins in the medicine, food, and pharmaceutical industries.

For example, acetylated pectins can be used as stabilizers and emulsifiers of food systems, as well as affect the release mechanism of ibuprofen (a weakly acidic drug) throughout the gastrointestinal tract.

The highly gelling properties of amidated pectins allows the manufacture of hydrogel beads that can be used for the delivery of drugs specific to the colon (such as indomethacin and sulfamethoxazole) and oral administration of insulin.

Thiolated pectins are promising for the use as mucoadhesive polymers. This property allows for a much deeper penetration of the drug (timolol maleate) through the cornea of the eye, which opens up the possibility of using modified pectins in ophthalmology.

Sulphated pectins are of interest due to their significant effect on the physiological functions of polysaccharides, such as antioxidant, anti-inflammatory, antitumour, antimicrobial, and antiviral (anti-HIV infectious activity). One of the characteristics of pectin sulphate is its anticoagulant activity and antithrombotic action. The studies have shown that the substitution of the carboxyl group with the sulphate group in citrus pectin increased both effects described above without affecting the hemorrhagic effect. In addition, this pectin derivative also exhibits improved antimicrobial action against Bacillus cereus and Vibrio fischeri.

The available methods for modifying pectin polysaccharides reveal the possibility of more effective practical use of natural biopolymers of carbohydrate nature not only in the food and cosmetic industry, but also for medical purposes. The search for new methods of changing the chemical structure of glycans contributes to the production of substances with desired properties, which have yet to be investigated on a larger scale.
\end{abstract}

Keywords: pectins, alkylation, amidation, thiolation, sulfation, use in medicine.

\section{References}

1. Harholt J., Suttangkakul A., Scheller H., Plant Physiology,2010, Vol. 153, pp. 384-395.

2. Mohnen D., Curr Opin Plant Biol., 2008, Vol. 11(3), pp. 266-277.

3. Zandleven J., Sorensen S., Harholt J., Beldman G. et al., Phytochemistry, 2007, Vol. 68, pp. 1219-1226.

4. Hart D., Kindel P., Biochem J., 1970, Vol. 116, pp. 569-579.

5. Ovodov Y., Ovodova R., Bondarenko O., Krasikova I., Carbohydr Res., 1971, Vol. 18, pp. 311-318.
6. Longland J., Fry S., Trewavas A., Plant Physiol., 1989, Vol. 90, pp. 972-976.

7. Khalikov D.Kh., Mirzoeva R.S., Bobodzhonova G.N., Gorshkova R.M. et al., Doklady Akademii nauk Respubliki Ta-dzhikistan, 2017, Vol. 60, No 7-8, pp. 333-341.

8. Li F.T., Yang H., Zhao Y., Xu R., Chinese Chemical Letters, 2007, Vol. 18, pp. 325-328.

9. Ignat'eva G.N., Ovsyuk T.I., Khranenie i pererabotka sel'khozsyr'ya, 2001, No 8, pp. 2731.

10. Rogozhnikov N.A., Kalmykova E.N., 
Arkhipova A.A., Fundamental'naya glikobiologiya, 2018, pp. 102-110.

11. KHalikova M.D., Diss. kand. med. Nauk, Dushanbe, 2009, 24 p.

12. Mironenko N.V., Brezhneva T.A., SHkutina I.V., Selemenev V.F., Sorbtsionnye i khromatograficheskie protsessy, 2015, Vol. 15, No 1, pp. 74-84.

13. Chen J., Liu W., Liu C., Li T. et al, Critical Reviews in Food Science and Nutrition, 2015, Vol. 55(12), pp. 1684-1698.

14. Kohn R., Furda I., Collection of Czechoslovak Chemical Communications, 1968, Vol. 42, pp. 731-744.

15. Kohn R., Malovikova A., Collection of Czechoslovak Chemical Communications, 1978, Vol. 43, pp. 1709-1719.

16. Renard C., Jarvis M., Carbohydrate Polymers, 1999, Vol. 39, pp. 209-216.

17. Leroux J., Langendorff V., Schick G., Vaishnav V. et al., Food Hydrocolloids, 2003, Vol. 17, pp. 455-462.

18. Monfregola L., Bugatti V., Amodeo P., De Luca S. et al., Biomacromolecules, 2011, Vol. 12, pp. 2311-2318.

19. Munjeri O., Collett J., Fell J., Journal of Controlled Release, 1997, Vol. 46, pp. 273-278.

20. Musabayane C., Munjeri O., Bwititi P., Osim E., Journal of Endocrinology, 2000, Vol.

Мамедов Элмаддин Исаевич - магистрант кафедры химии, Липецкий государственный технический университет, Липецк

Дергунова Елена Сергеевна - доцент кафедры химии, к.Х.н., Липецкий государственный технический университет, Липецк

Калмыкова Елена Николаевна - доцент кафедры химии, д.х.н., Липецкий государственный технический университет, Липецк
164, pp. 1-6.

21. Sharma R., Ahuja M., Carbohydrate Polymers, 2011, Vol. 85, pp. 658-663.

22. Sharma R., Ahuja M., Kaur H., Car-bohydrate Polymers, 2012, Vol. 87, pp. 1606-1610.

23. Fan L., Gao S., Wang L., Wu P. et al., Journal of Applied Polymer Science, 2012, Vol. 124, pp. 2171-2178.

24. Maas N., Gracher A., Sassaki G., Gorin P. et al., Carbohydrate Polymers, 2012, Vol. 89, pp. 1081-1087.

25. Vityazev F., Golovchenko V., Patova O., Drozd N. et al., Biochemistry, 2010, Vol. 75, pp. 759-768.

26. Takano R., Nagai T., Wu X., Xu X. et al., Journal of Carbohydrate Chemistry, 2000, Vol. 19, pp. 1185-1190.

27. Vityazev F.V., Golovchenko V.V., Patova O.A., Drozd N.N. et al., Biokhimiya, 2010, Vol. 75, No 6, pp. 857-867.

28. Mahner C., Lechner M., Nordmeier E.. Carbohydrate Research, 2001, Vol. 33, pp. 203208.

29. Vogt S., Heinze T., Rottig K., Klemm D., Carbohydrate Research, 1995, Vol. 266, pp. 315-320.

30. Bae I., Joe Y., Rha H., Lee S. et al., Food Hydrocolloids, 2009, Vol. 23, pp. 1980-1983.

Mamedov Elmaldin I. - master's student, department of chemistry, Lipetsk State Technical University, Lipetsk, e-mail: elik.mam@mail.ru

Dergunova Elena S. - Ph.D. (chemistry), associate prof., department of chemistry, Lipetsk State Technical University, Lipetsk, e-mail: dergunova14@yandex.ru

Kalmykova Elena N. - Doctor of Chemical Sciences, associate prof., department of chemistry, Lipetsk State Technical University, Lipetsk, e-mail: veter1407@,rambler.ru 